\title{
O PROFMAT NO CAMPUS DE TRÊS LAGOAS DA UNIVERSIDADE FEDERAL DE MATO GROSSO DO SUL NO PERÍODO DE 2012 A 2021: ENTRE DIÁLOGOS, ASPECTOS E IMPACTOS
}

\section{THE PROFMAT AT THE TRÊS LAGOAS CAMPUS OF THE FEDERAL UNIVERSITY OF MATO GROSSO DO SUL FROM 2012 TO 2021: BETWEEN DIALOGS, ASPECTS AND IMPACTS}

\author{
Eugenia Brunilda Opazo Uribe ${ }^{1}$ \\ Fernando Pereira de Souza² \\ Antonio Carlos Tamarozzi ${ }^{3}$
}

\begin{abstract}
RESUMO: O presente trabalho apresenta resultados de uma pesquisa sobre o oferecimento do Mestrado Profissional em Matemática em Rede Nacional (Profmat), no campus de Três Lagoas da Universidade Federal de Mato Grosso do Sul no período de 2012 a 2021, visando identificar alguns aspectos importantes sobre o perfil do aluno que procura o Profmat no campus, bem como evidenciar impactos na vida profissional dos egressos do programa. A pesquisa foi iniciada por uma análise de documentos, considerando os dados disponíveis sobre o programa, registros da coordenação de curso e informações disponíveis na Plataforma Sucupira. A continuidade do trabalho foi feita por meio da aplicação de um questionário on-line aos egressos do curso, com perguntas objetivas e abertas, utilizando metodologia descritiva. Foram obtidas 43 respostas, que indicaram um grau de satisfação importante com o curso realizado, bem como um aumento de oportunidades para os participantes que, além de se manterem na docência na educação básica, passaram a ocupar outros espaços, atuando tanto no ensino técnico quanto no ensino superior.
\end{abstract}

PALAVRAS-CHAVE: Mestrado Profissional. Matemática. Egressos.

\begin{abstract}
The present paper presents the results of a research on the offering of the National Networked Professional Master's Degree in Mathematics (Profmat), at the Três Lagoas campus of the Federal University of Mato Grosso do Sul from 2012 to 2021, aiming to identify some important aspects about the profile of the student who seeks Profmat on campus, as well as to highlight impacts on the professional of the program's graduates. The research was initiated by an analysis of documents. Considering the available data on the program, course coordination records and information available on the Sucupira Platform. The continuity of the work was done by applying an online questionnaire to the course graduates, with objective and open questions, using a descriptive methodology. Forty-three responses were obtained, indicating an important degree of satisfaction with the course taken, as well as an increase in opportunities for the participants who, besides continuing to teach in basic education, began to occupy other spaces, working in both technical and higher education.
\end{abstract}

KEYWORDS: Professional Master's Degree. Mathematics. Graduates.

\footnotetext{
1 Universidade Federal de Mato Grosso do Sul. E-mail: eugenia.uribe@ufms.br

(1) http://orcid.org/0000-0002-9517-0007

2 Universidade Federal de Mato Grosso do Sul. E-mail: fernando.pereira@ufms.br

(1) https://orcid.org/0000-0001-6441-0103

3 Universidade Federal de Mato Grosso do Sul. E-mail: antonio.tamarozzi@ufms.br

(i) https://orcid.org/0000-0001-7612-6302

- Informações completas da obra no final do artigo
} 


\section{Introdução}

O Campus de Três Lagoas (CPTL) da Universidade Federal de Mato Grosso do Sul (UFMS), inserido na região leste do Estado, nasceu como um Centro Pedagógico em janeiro de 1970, pela Lei Estadual no 2.972, com o oferecimento dos cursos de Licenciatura Plena em Geografia, História, Letras, Matemática e Pedagogia (UFMS, 2019, p. 5).

A experiência de trabalho em formação inicial de professores, no Curso de Licenciatura em Matemática, levou à aproximação da universidade com a escola de educação básica, por meio do oferecimento de cursos de especialização e projetos de extensão, dentre os quais pode-se destacar o oferecimento do Programa de Aperfeiçoamento de Professores do Ensino Médio (PAPMEM), considerado por Viana (2018) como o principal predecessor do Profmat.

O principal predecessor foi o PAPMEM (Programa de Aperfeiçoamento de Professores do Ensino Médio), programa que oferece atividades de formação continuada a professores do Ensino Médio, por meio de dois encontros com uma duração de uma semana, todo ano, em janeiro e em julho. Lançado em 1990 por iniciativa do diretor do IMPA, professor Elon Lages Lima, o PAPMEM vem funcionando ininterruptamente desde então e, mais recentemente, adquiriu uma dimensão nacional por meio de transmissão à distância, para cerca de 50 polos em todos os estados, das aulas produzidas no IMPA (VIANA, 2018, p. 135).

Essa aproximação permitiu conhecer a realidade dos professores de Matemática da Educação Básica da cidade de Três Lagoas e de algumas cidades da região. Cientes dos anseios desses professores por aperfeiçoamento tanto na área da Matemática, como na área do Ensino de Matemática, os professores de Matemática da UFMS/CPTL decidiram pela participação no projeto do Mestrado Profissional em Rede Nacional (Profmat). A UFMS já estava credenciada na rede de oferecimento do Profmat, desde seu início, em 2011, com a coordenação e oferecimento do curso no campus de Campo Grande. Considerando os aspectos relatados e a forte procura, houve uma mobilização dos professores do curso de Matemática da UFMS/CPTL junto a Pró-Reitoria de Pós Graduação da Universidade e à coordenação do Profmat para a implantação do Programa no campus local, conforme ofício da Sociedade Brasileira de Matemática (SBM) informando a composição da Rede de Instituições do Profmat ao Diretor de Avaliação da Coordenação de Aperfeiçoamento de 
Pessoal de Nível Superior (CAPES), em 12 de dezembro de 2011 (SOCIEDADE BRASILEIRA DE MATEMÁTICA, 2011a).

$\mathrm{E}$ assim o primeiro edital de chamada para o processo seletivo de ingresso no Profmat/UFMS/CPTL foi publicado, disponibilizando 15 vagas para início das aulas em 2012. A valorização da comunidade local, aliada à credibilidade da UFMS e à organização e prestígio da SBM, faz com que o interesse pelo curso continue alto até os dias de hoje.

A partir da turma de 2020, a SBM fez o desmembramento dos polos formados por campi da mesma instituição e, dessa maneira, Três Lagoas passou a ser um polo independente entre as instituições associadas nacionalmente para o oferecimento do Profmat.

O objetivo deste artigo é apresentar resultados sobre o oferecimento do Profmat na UFMS/CPTL no período 2012 a 2021, visando identificar alguns aspectos importantes sobre o perfil do aluno que procura o Profmat na UFMS/CPTL, bem como evidenciar impactos na vida profissional e laboral dos egressos do programa.

\section{METODOLOGIA}

Para atingir o objetivo proposto, foi realizada inicialmente uma análise documental, considerando dados disponíveis na página do programa (PROFMAT, 2021), bem como alguns registros da coordenação do curso da UFMS/CPTL e informações disponibilizadas na plataforma Sucupira. ${ }^{4}$

Numa segunda etapa foi realizada uma coleta de dados com egressos do programa no polo da UFMS/CPTL, que foram convidados para participar desse levantamento, via email ou telefone, sendo que 43 egressos aceitaram o convite. Considerando o contexto da pandemia da covid-19 o levantamento de dados foi realizado on-line utilizando como instrumento um questionário com 10 questões objetivas e 4 questões abertas. $\mathrm{O}$ uso de questionários apresenta uma série de vantagens como por exemplo, alcance, economia de tempo e o preenchimento obrigatório de perguntas, entre outras. Em contrapartida,

${ }_{4}^{4}$ Disponível em: https://sucupira.capes.gov.br/sucupira/ 9. Acesso em: 19 nov. 2021. 
apresenta algumas desvantagens dentre as quais se destaca a baixa taxa de resposta. Segundo Takai (2017) a média de devolução de respostas de questionário é de 25\%.

Para todos os entrevistados foi apresentado o contexto da pesquisa descrito no Termo de Consentimento Livre e Esclarecido (TCLE), por meio do qual os participantes manifestaram sua concordância em relação à participação na pesquisa e autorizaram que os resultados fossem publicados, preservando o sigilo dos entrevistados e suas instituições de trabalho.

Assim, trata-se de um estudo de cunho quantitativo que, por esse motivo, foi conduzido de uma maneira descritiva, visando apresentar características e estabelecer conexões a partir dos dados discutidos.

A pesquisa descritiva observa, registra, analisa e correlaciona fatos ou fenômenos (variáveis) sem manipulá-los. Procura descobrir, com precisão possível, a frequência com que um fenômeno ocorre, sua relação e conexão com outros, sua natureza e características (MANZATO; SANTOS, p. 4).

De acordo com essa descrição os autores do presente trabalho concentraram esforços em coletar dados e informações, que apresentam as características, dificuldades e desafios que afetam o trabalho realizado, bem como permitem conhecer melhor a comunidade atendida pelo programa na UFMS/CPTL.

\section{O PROFMAT NA UFMS/CPTL}

O Profmat é o primeiro mestrado profissional oferecido em rede nacional que, de acordo com a apresentação que pode ser encontrada na página oficial do programa (PROFMAT, 2021), visa atender prioritariamente professores de Matemática em exercício na educação básica, especialmente de escolas públicas, que busquem aprimoramento em sua formação profissional, com ênfase no domínio aprofundado de conteúdo matemático relevante para sua docência, conforme estabelece o regimento do Programa, no seu artigo primeiro.

O Mestrado Profissional em Matemática em Rede Nacional (PROFMAT) tem como objetivo proporcionar formação matemática aprofundada relevante ao exercício da docência no Ensino Básico, visando dar ao egresso qualificação certificada para o exercício da profissão de professor de Matemática (SBM, 2011, p. 1)

O oferecimento do Profmat representou uma mudança no acesso aos programas de pós-graduação que, até então era muito restrito. Takai (2017) em sua tese de doutorado 
analisa o processo de criação do Profmat, descrevendo inclusive as mudanças legais que foram implementadas para que o oferecimento de um mestrado profissional em rede nacional fosse possível. A autora destaca que

O surgimento de um programa nos moldes do PROFMAT somente foi possível devido às mudanças estruturais e culturais na concepção de programas de pósgraduação stricto sensu, numa ação induzida pelo Estado, representado pela CAPES. De cursos elitizados e para a minoria, em sua gênese, com os mestrados profissionais em rede para professores, como o PROFMAT, o acesso à pósgraduação ampliou-se vertiginosamente para um público diverso [...] (TAKAI, 2017, p. 26).

A experiência do campus de Três Lagoas reforça essa afirmação, visto que, desde o início o curso, houve uma boa procura por professores que manifestavam interesse em realizar cursos de aperfeiçoamento e para os quais a realização de um mestrado era um sonho distante. O polo não atende apenas a cidade de Três Lagoas, mas toda a região, composta pelo leste do Estado Mato Grosso do Sul e o Noroeste do Estado de São Paulo, tendo atendido diversas cidades conforme apresentado no mapa da Figura 1.

Figura 1. Cidades atendidas pelo Profmat em Três Lagoas

Fonte. Os autores, 2021.

Ao analisar as matrículas, pode-se verificar que o programa já atendeu 148 alunos, provenientes de 7 cidades de Mato Grosso do Sul, 24 cidades de São Paulo e 1 cidade de Minas Gerais. A maioria dos alunos matriculados são oriundos de cidades do interior do 
estado de São Paulo, representando 60,81\% das matrículas, seguido dos alunos procedentes de cidades de Mato Grosso do Sul que representam 37,83\% das matrículas e por último matriculados com origem em uma cidade de Minas Gerais que representam $1,35 \%$ das matrículas. A margem entre paulistas e sul-mato-grossenses diminui quando são analisados os números sobre os titulados, já que neste caso, os alunos titulados oriundos do estado de São Paulo representam um 59,25\% dos titulados, enquanto os procedentes de Mato Grosso do Sul representam 40,74\% dos titulados.

Cabe destacar que a maioria dos professores continuaram trabalhando enquanto realizavam o mestrado; desse modo, a matrícula no Profmat na UFMS/CPTL levava os professores a percorrer semanalmente grandes distâncias para participar de aulas e atividades em Três Lagoas. Na Tabela 1 são destacadas algumas cidades, sua distância a Três Lagoas e o número de titulados da cidade.

\begin{tabular}{|l|c|c|}
\hline \multicolumn{3}{|c|}{ Tabela 1. Cidades, distâncias e número de titulados. } \\
\hline \multicolumn{1}{|c|}{ Cidade } & Distância de Três Lagoas & Titulados \\
\hline Américo de Campos & $262,4 \mathrm{~km}$ & 1 \\
\hline Anastácio & $463,6 \mathrm{~km}$ & 1 \\
\hline Aparecida do Taboado & $128,6 \mathrm{~km}$ & 5 \\
\hline Araçatuba & $149,5 \mathrm{~km}$ & 9 \\
\hline Birigui & $167,0 \mathrm{~km}$ & 2 \\
\hline Penápolis & $199,8 \mathrm{~km}$ & \\
\hline Fonte: Dados da Coordenação de Curso. \\
\hline
\end{tabular}

A Tabela 1 destaca algumas cidades distantes de Três Lagoas que foram atendidas pelo Curso do Profmat/CPTL, mostrando que a distância percorrida semanalmente por alguns professores superava os $120 \mathrm{~km}$ para participar das atividades presenciais.

O campus de Três Lagoas da UFMS conta com um corpo de professores reduzido na área de Matemática, assim, para evitar um aumento inesperado da carga horária, os professores responsáveis pela iniciativa organizaram inicialmente uma parceria com professores do Campus de Paranaíba (CPAR). Inicialmente, a responsabilidade pelas disciplinas foi dividida com 10 professores, que ministravam as aulas em regime de revezamento ou divisão de carga-horária. Atualmente, considerando disciplinas obrigatórias e optativas, cada uma está sob a responsabilidade de um professor fixo, vinculado ao campus CPTL, totalizando sete professores participantes. Esse quadro docente também é responsável pela orientação dos trabalhos de conclusão de curso (dissertações). 
Atendendo o oferecimento semipresencial previsto no regimento do Programa as disciplinas, obrigatórias e optativas, foram oferecidas por meio de aulas presenciais aos sábados até 2019. Em 2020 e em 2021, devido ao contexto da pandemia da covid-19, as aulas foram oferecidas de forma on-line, valendo-se do uso de plataformas como o Google Meet e o Ambiente Virtual de Aprendizagem (AVA) da UFMS.

\section{RESPOSTAS DOS EGRESSOS DO PROFMAT POLO UFMS/CPTL}

A coleta de dados com egressos do Profmat da UFMS/CPTL foi realizada mediante a aplicação de um formulário on-line, com a apresentação da pesquisa e Termo de Consentimento Livre e Esclarecido (TCLE). Os entrevistados foram questionados quanto à formação inicial e o tipo de Instituição de Ensino Superior em que se formaram como professores. Além disso, informaram sua ocupação principal antes e depois da conclusão do curso; avaliaram a experiência de terem participado no Profmat, o impacto do Programa na formação profissional; mudança salarial após a conclusão; os entrevistados foram questionados também sobre alguma disciplina ou tópico diferente que considerassem interessante de ser explorado nas disciplinas optativas e também foi aberto um espaço para que deixassem comentários sobre questões que não tivessem sido abordados pelas questões apresentadas. De 54 titulados, foram obtidas 43 respostas, o que representa $79,63 \%$ do total e podemos considerar uma boa taxa de resposta, uma vez que está bem acima da média descrita por Takai (2017).

A amostra trabalhada também demonstrou a predominância masculina entre os entrevistados, já que $72,1 \%$ dos egressos que responderam à pesquisa são homens e 27,9\% são mulheres. Trata-se de um resultado comparável ao obtido em nível nacional, apresentado pela Sociedade Brasileira de Matemática, que verificou que "A distribuição dos egressos quanto ao gênero demostra que há grande predominância do sexo masculino (80\%) e apenas $20 \%$ dos egressos são do sexo feminino." (2017, p. 22). 


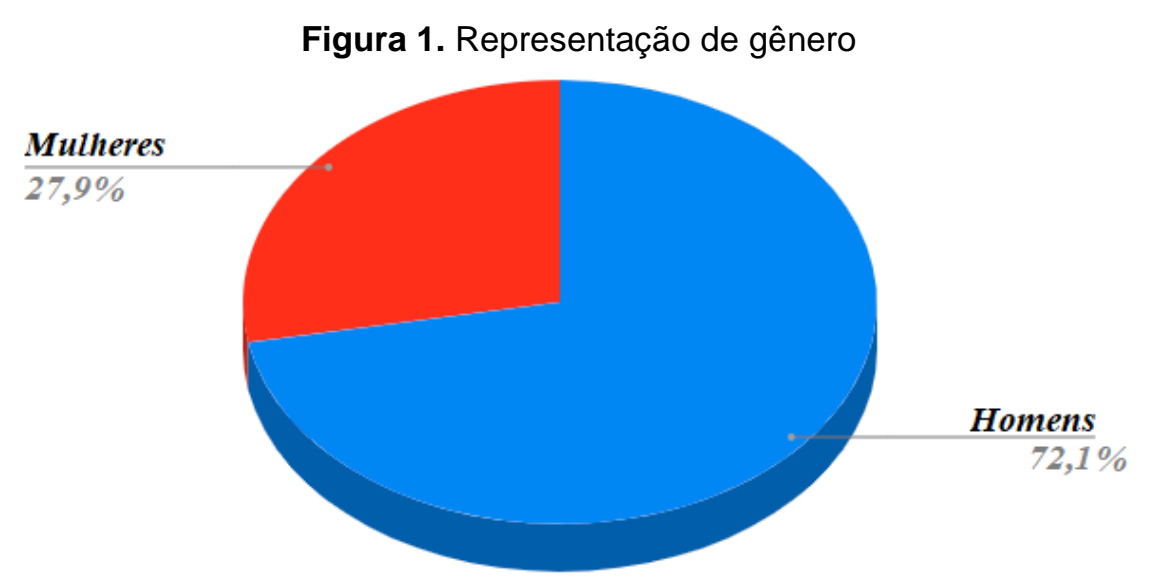

Fonte: Os autores, 2021.

É importante destacar que os resultados apresentados por Brech $(2018$, p. 1) já indicavam esse desequilíbrio "Em quase todos os recortes da comunidade matemática no mundo, a participação feminina fica abaixo de 50\% e diminui nos estágios mais avançados da carreira". A pesquisadora apresenta dados referentes à Pós-Graduação de 2014 e conclui "Na pós-graduação, as mulheres perfizeram em 2014 em torno de $27 \%$ entre os egressos de cursos de mestrado e $24 \%$ entre os de doutorado. As séries históricas [...] indicam que esses percentuais não estão aumentando." Brech (2018, p. 2).

Sobre a formação inicial, foi possível identificar que todos os entrevistados têm formação em Licenciatura, vinculada à área de Ciências Exatas, sendo que a maioria é formado em Licenciatura em Matemática, tendo como outras possibilidades a Licenciatura em Ciências com habilitação em Matemática e a Licenciatura em Física.

Figura 2. Formação Inicial dos entrevistados

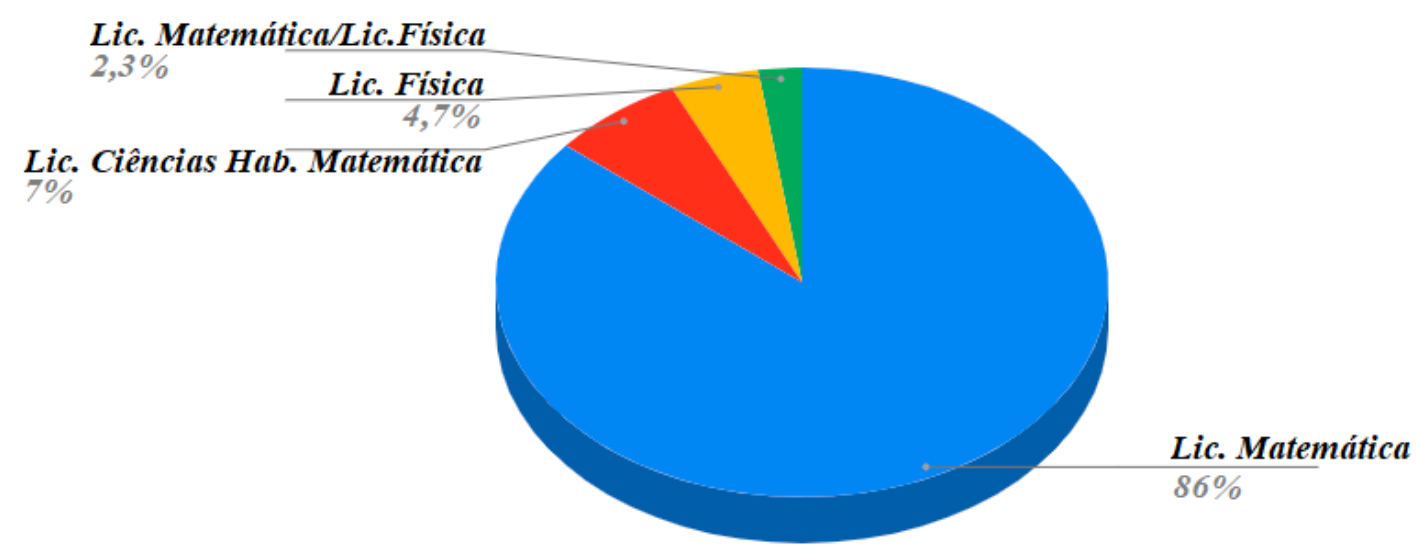

Fonte: Os autores, 2021. 
Ainda em relação à formação inicial, as Instituições de Ensino Superior em que os entrevistados concluíram a graduação são variadas e localizadas no leste do Estado de Mato Grosso do Sul e Noroeste Paulista, com predominância de instituições públicas, conforme apresentado na Figura 3.

Figura 3. Instituições de Formação dos entrevistados

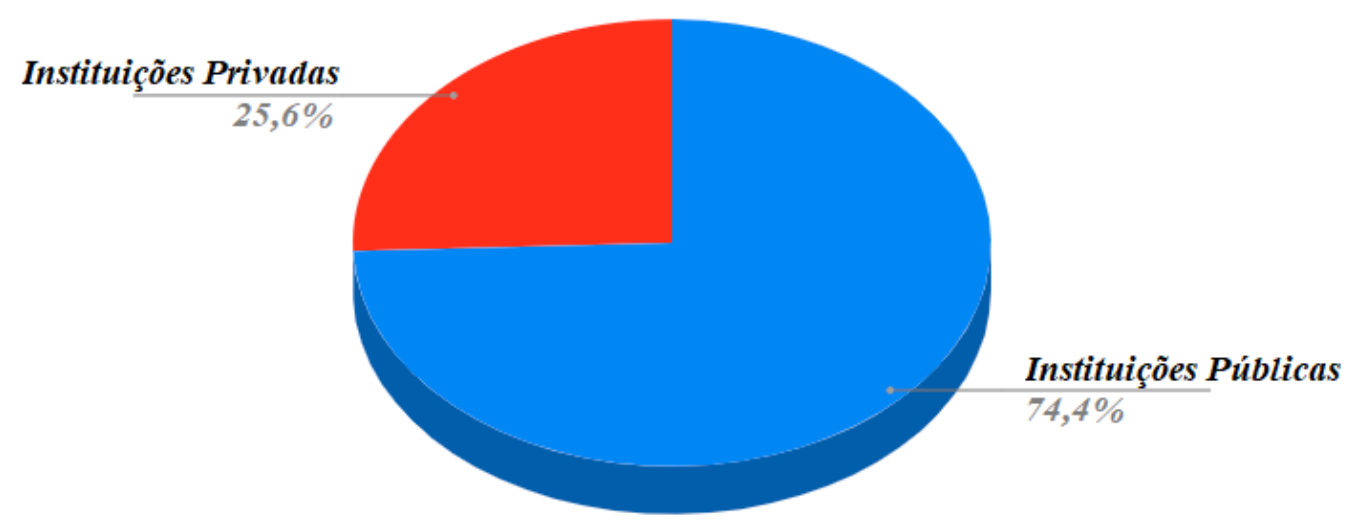

Fonte: Os autores, 2021.

Os entrevistados foram consultados também sobre sua ocupação principal antes de realizar o Profmat, como esperado, a maioria deles atuava como professor de educação básica, conforme indicado na Figura 4; mais especificamente 86\% atuavam como professores de Educação Básica, enquanto 14\% não atuavam como professores de educação básica.

Figura 4. Ocupação principal dos entrevistados antes do PROFMAT

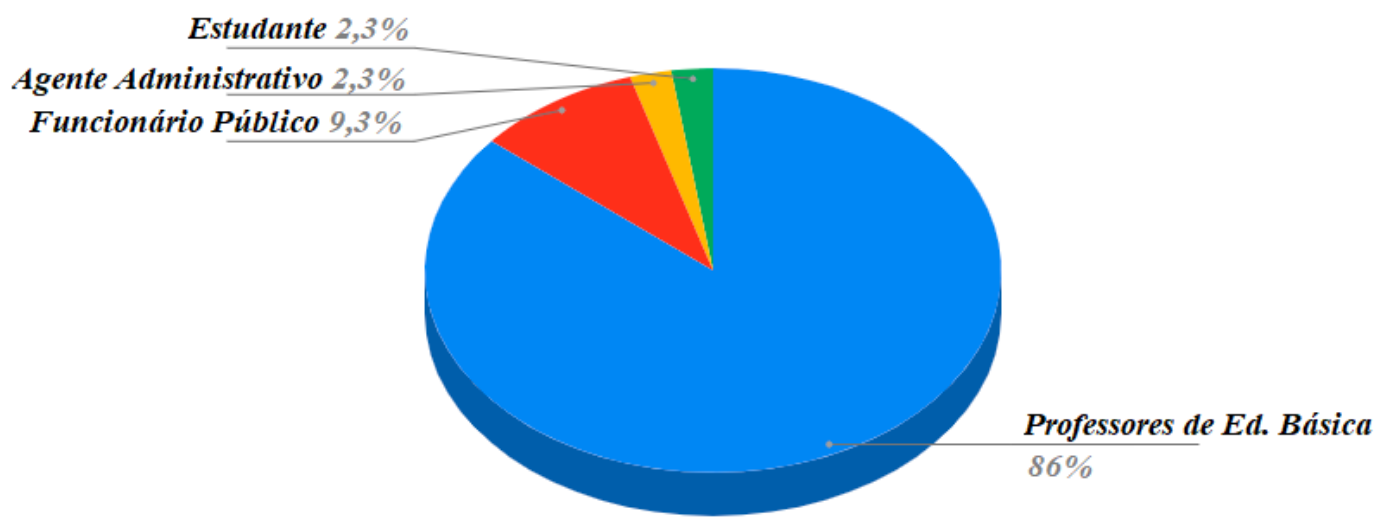

Fonte: Os autores, 2021. 
Buscando estabelecer se houve mudanças em relação à ocupação principal e, principalmente, se os entrevistados continuavam atuando na docência, eles foram questionados quanto à função exercida após a realização do Profmat. Os resultados são apresentados na Figura 5 e eles indicam que $83,7 \%$ dos entrevistados continua trabalhando na docência, enquanto 16,3\% não exerce essa atividade.

Foi possível verificar que, após a realização do Profmat, os entrevistados passaram a ocupar espaços em outros níveis do ensino, incluindo ensino técnico e superior.

Figura 5. Ocupação principal dos entrevistados após a realização do PROFMAT

Professor Ensino Técnico 2,3\%

Professor Ensino Técnico e Superior 2,3\%

Professor Educ. Básica outra disciplina 4,7\%

Professor Educ. Básica e Superior 9,3\%

Professor de Educ. Básica, Técnica e Superior

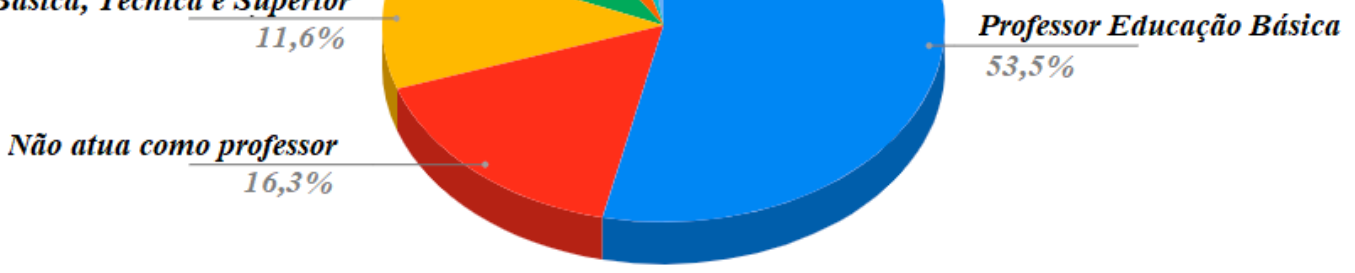

Fonte: Os autores, 2021.

Quanto à experiência de terem participado do curso e obtido o diploma de mestrado do Profmat, os entrevistados são unânimes na avaliação positiva, conforme ilustrado na figura 5 , destacando que a vivêbncia foi excelente ou muito boa.

Figura 5. Avaliação da participação no Profmat

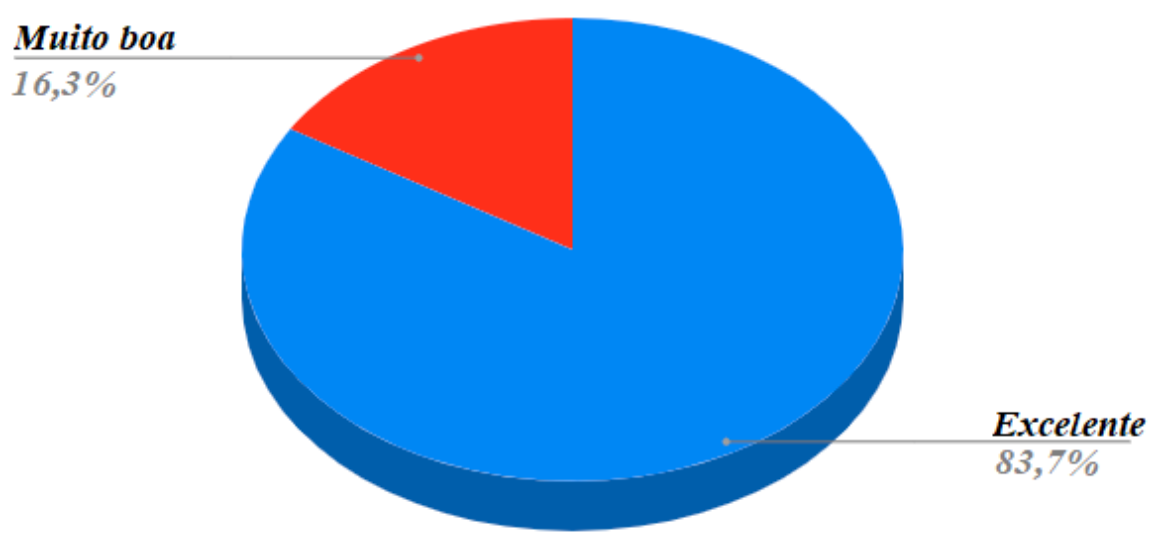

Fonte: Os autores, 2021. 
Nas questões abertas, os egressos foram perguntados sobre o impacto da realização do curso na formação profissional e a situação laboral. Ademais, informaram quais disciplinas ou conteúdos que gostariam que fossem explorados e o que poderia ser melhorado no curso. Apesar das questões serem abertas houve coincidência em algumas respostas, assim, elas podem ser sistematizadas sistematizadas conforme disposto no Quadro 1:

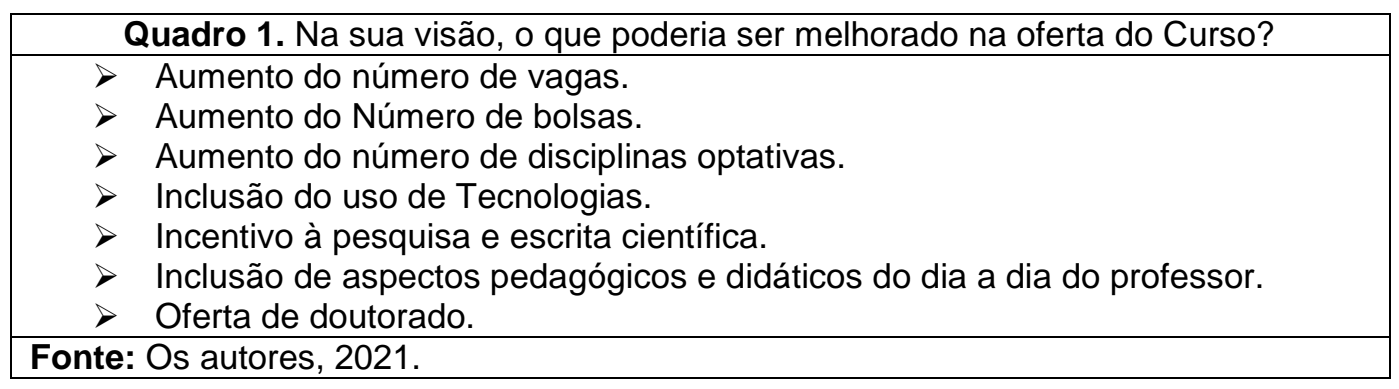

Cabe observar que algumas destas questões aparecem em relatórios nacionais, como por exemplo a solicitação de oferta de doutorado, "[...] que recebeu 118 sugestões, correspondente a $18 \%$ dos respondentes", o que "[...] ajuda a reforçar o sucesso e reconhecimento do Profmat entre os discentes e deve ser avaliada" (SBM, 2017, p. 46). A questão de inclusão de aspectos pedagógicos e didáticos do dia a dia do professor e sua prática em sala de aula também foi destaque no relatório nacional, sendo que $84 \%$ dos que mencionam o assunto "[...] faz referência apenas à inclusão desse tipo de disciplina, o que pode ser avaliado se complementa ou não os objetivos do Profmat" (SBM, 2017, p. 46).

Em relação ao impacto na vida profissional e laboral, os egressos são unânimes em destacar o impacto positivo da realização do Profmat e os resultados podem ser observados no Quadro 2. A resposta "Conhecimentos mais sólidos, maior embasamento teórico, melhor visão em relação à aplicações da Matemática" foi a mais lembrada pelos respondentes da pesquisa, o que indica que o objetivo do Profmat de atender professores da Educação Básica que busquem aprimoramento em sua formação profissional, com ênfase no domínio aprofundado de conteúdo matemático relevante para sua docência está sendo atingido. 


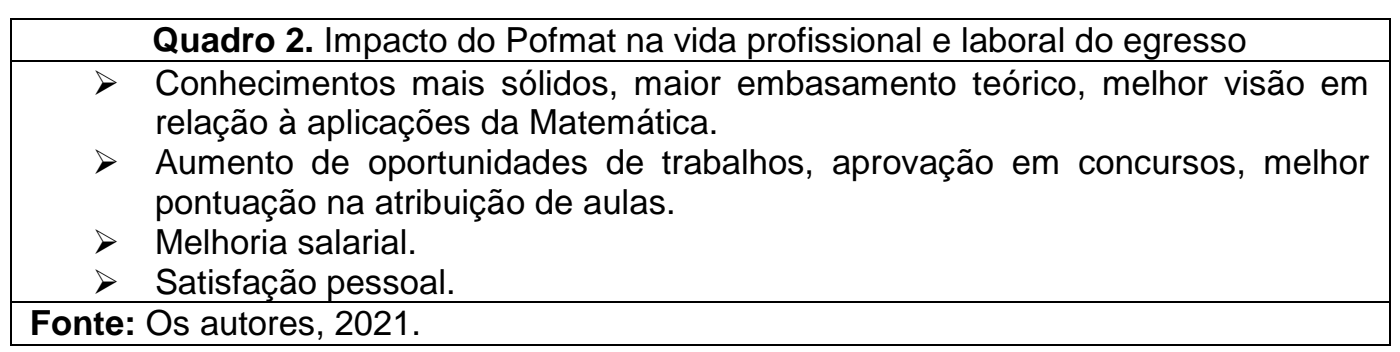

Em relação aos conteúdos não abordados pelo programa e que gostariam que fossem mais explorados, as respostas foram sistematizadas e são apresentadas no Quadro 3. O resultado mais lembrado pelos respondentes foi "não acrescentaria outros tópicos" mostrando que existe um grau de satisfação com o curso realizado.

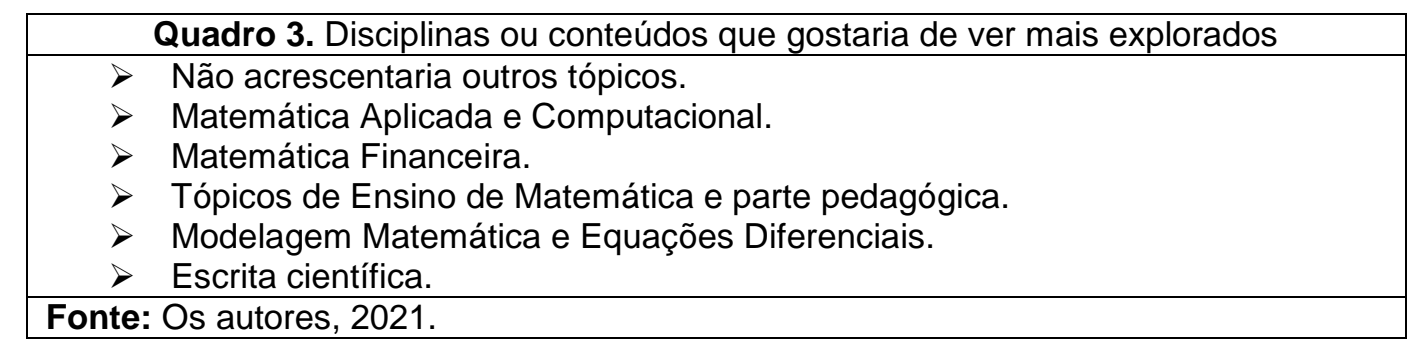

A última questão aberta apresentou a possibilidade de que os egressos tecessem algum comentário ou dessem alguma sugestão quanto a algum tópico não contemplado nos questionamentos anteriores. Neste espaço novamente foi colocada a possibilidade da oferta de um doutorado e também foram recebidos muitos elogios e agradecimentos ao corpo de professores do Profmat do Polo da UFMS/CPTL, reforçando a avaliação positiva do curso e da atuação dos professores do programa.

\section{Considerações Finais}

O trabalho de pesquisa buscou fazer um levantamento de dados sobre os 10 anos do Profmat no Campus de Três Lagoas da UFMS, mediante a revisão de documentos da coordenação, da Plataforma Sucupira e das respostas obtidas através da aplicação de um questionário on-line enviado aos egressos, que obteve 43 respostas, representando $79,63 \%$ do total de alunos titulados. A análise das respostas permitiu identificar alguns aspectos importantes sobre o perfil do aluno que procura o curso, bem como evidenciar impactos na vida profissional e laboral dos egressos do programa. 
Analisando o recorte de gênero, os dados indicam a predominância masculina entre os entrevistados, obtendo-se que $72,1 \%$ dos egressos que responderam à pesquisa são homens e 27,9\% são mulheres. Estes resultados são compatíveis com dados disponíveis na literatura, como os apresentados por Brech (2018) e que reforçam a compreensão de que iniciativas que evidenciem a desigualdade de gênero na área de Matemática são importantes e devem ser apoiadas, visando potencializar a participação feminina na área de Matemática e Ciências Exatas em geral.

A partir dos dados disponibilizados pela coordenação de curso foi possível perceber que o polo de Três Lagoas/MS, localizado na fronteira entra São Paulo e Mato Grosso do Sul, conta com um posicionamento estratégico que permite atender professores de diversas cidades localizadas numa região composta pelo leste de Mato Grosso do Sul e o Noroeste Paulista. Os dados mostram ainda que entre os alunos titulados existem vários casos em que as distâncias percorridas entre a cidade de origem e Três Lagoas, local de realização do curso, superavam os $120 \mathrm{~km}$.

Sobre a ocupação principal dos egressos que responderam o questionário, foi possível verificar que $86 \%$ atuavam como professores de Educação Básica antes da realização do Profmat e após a conclusão do curso, 83,7\% continuava trabalhando na docência, porém após a realização do Profmat, parte dos entrevistados passaram a ocupar espaços também em outros níveis do ensino, incluindo ensino técnico e superior.

A abertura de oportunidades no exercício da profissão, bem como a maior segurança em relação aos próprios conhecimentos, devido a apropriação de um maior embasamento teórico motivou respostas positivas em relação à experiência de ter realizado o mestrado, levando os participantes a considerá-la como excelente e muito proveitosa.

Nesse sentido, os resultados do trabalho mostram que o Profmat atinge seu objetivo de proporcionar aos professores uma formação matemática aprofundada relevante ao exercício da docência no Ensino Básico, mas também apontam a existência de espaço para discussão e crescimento. As respostas dos egressos do CPTL permitem destacar três questões importantes para discussões futuras sobre o Profmat: a inclusão do dia a dia do professor e sua prática pedagógica; o incentivo à leitura e escrita de artigos que aproximem o mestrando da pesquisa acadêmica e a possibilidade de oferecimento de doutorado.

Por fim, espera-se que o presente estudo possa contribuir para que a coordenação do curso conheça com mais profundidade o perfil dos egressos, permitindo avaliar a 
necessidade de implementação de intervenções curriculares. É importante destacar também que durante o desenvolvimento do trabalho surgiram outras questões para serem analisadas, o que justifica, no futuro, a continuidade do estudo.

\section{Referências}

BRECH, C. O 'dilema Tostines' das mulheres na matemática. Revista Matemática Universitária No. 54. 2018. Disponível em: https://rmu.sbm.org.br/wpcontent/uploads/sites/27/2018/08/kika_final.pdf. Acesso em: 15 nov. 2021.

\section{MANZATO, A. J; SANTOS, A. B. A Elaboração de Questionários na Pesquisa} Quantitativa. Minicurso. 2002. Disponível em:

http://www.inf.ufsc.br/ vera.carmo/Ensino_2012_1/. Acesso em: 30 nov. 2021.

SOCIEDADE BRASILEIRA DE MATEMÁTICA. PROMAT: Uma Reflexão e alguns Resultados. Rio de Janeiro: SBM, 2017. Disponível em: https://profmatsbm.org.br/documentos/. Acesso em: 30 nov. 2021.

SOCIEDADE BRASILEIRA DE MATEMÁTICA. Regimento do Mestrado Profissional em Matemática em Rede Nacional. Rio de Janeiro: SBM, 2011a.

Disponível em: https://profmat-sbm.org.br/documentos/. Acesso em: 15 nov. 2021.

SOCIEDADE BRASILEIRA DE MATEMÁTICA. Ofício 003/2011 - PROFMAT/SBM. Rio de Janeiro, 2011b. Disponível em: https://profmat-sbm.org.br/documentos/. Acesso em: 20 nov. 2021.

TAKAI, A. M. Perspectivas do Profmat: Política Pública em construção. 175f. Tese (Doutorado em Educação em Ciências: Química da Vida e da Saúde) - Instituto de Ciências Básicas da Saúde, Universidade Federal de Rio Grande do Sul, Porto Alegre, RS, 2017. Disponível em: https://www.lume.ufrgs.br/handle/10183/159502. Acesso em: 14 nov. 2021.

VIANA, M. Matemática no Ensino Médio: Desafios e Iniciativas. In: FOGUEL, D.; SCHEUENSTUHL, M. C. B. (Org.). Desafios da Educação Técnico-Científica no Ensino Médio. Rio de Janeiro: Academia Brasileira de Çiências, 2018, cap. 2, p. 130-140. Disponível em: http://www.abc.org.br/evento/desafios-da-educacao-tecnico-cientifica-noensino-medio/. Acesso em: 12 out. 2021.

NOTAS

IDENTIFICAÇÃO DE AUTORIA 
Eugenia Brunilda Opazo Uribe. Doutora em Engenharia Mecânica pela Universidade Estadual de Campinas (UNICAMP). Professora Associada da Universidade Federal de Mato Grosso do Sul (UFMS), Campus de Três Lagoas (CPTL). Três Lagoas, MS, Brasil.

E-mail: eugenia.uribe@ufms.br

(1) http://orcid.org/0000-0002-9517-0007

Fernando Pereira de Souza. Doutor em Matemática pela Universidade Estadual de Campinas. Professor Adjunto da Universidade Federal de Mato Grosso do Sul (UFMS), Campus de Três Lagoas (CPTL). Coordenador do Mestrado Profissional em Matemática em Rede Nacional/CPTL (Profmat) Três Lagoas, MS, Brasil.

E-mail: fernando.pereira@ufms.br

(iD) https://orcid.org/0000-0001-6441-0103

\section{Antonio Carlos Tamarozzi.}

Doutor em Matemática pela Universidade de Brasília (UnB). Professor Associado da Universidade Federal de Mato Grosso do Sul (UFMS), Campus de Três Lagoas (CPTL). Docente do Mestrado Profissional em Matemática em Rede Nacional/CPTL (Profmat), Três Lagoas, MS, Brasil.

E-mail: antonio.tamarozzi@ufms.br

(iD) https://orcid.org/0000-0001-7612-6302

\section{AGRADECIMENTOS}

Os autores agradecem à Universidade Federal de Mato Grosso do Sul.

\section{FINANCIAMENTO}

Não se aplica.

CONSENTIMENTO DE USO DE IMAGEM

Não se aplica.

\section{APROVAÇÃO DE COMITÊ DE ÉTICA EM PESQUISA \\ Não se aplica.}

\section{LICENÇA DE USO}

Autores mantêm os direitos autorais e concedem à revista ENSIN@ UFMS - ISSN 2525-7056 o direito de primeira publicação, com o trabalho simultaneamente licenciado sob a Licença Creative Commons Attribution (CC BY-NC-SA 4.0), que permite compartilhar e adaptar o trabalho, para fins não comerciais, reconhecendo a autoria do texto e publicação inicial neste periódico, desde que adotem a mesma licença, compartilhar igual.

\section{HISTÓRICO}

Recebido em: 20/11/2021 - Aprovado em: 12/12/2021 - Publicado em: 15/12/2021.

\section{COMO CITAR}

URIBE, E. B. O; SOUZA, F. P; TAMAROZZI, A. C. Título do Artigo. Revista ENSIN@ UFMS, Três Lagoas, v. 2, número especial, p. 29-43. 2021. 